\title{
Implantação de Campo Experimental para estudos de Mecânica dos Solos. Realização de sondagens em campo (SPT) e realização de ensaios laboratoriais
}

\section{Yoshiteru Motoshima Filho*, David de Carvalho.}

\section{Resumo}

Esta pesquisa tem por objetivo determinar as características geotécnicas do campo experimental da Faculdade de Engenharia Agrícola da Unicamp (FEAGRI) através dos ensaios de Standard Penetration Test (SPT), de granulometria, massa específica, limites de liquidez e limites de plasticidade, de modo a fornecer ao meio técnico os subsídios para a sua adequada utilização em Mecânica dos Solos. Assim, foram desenvolvidas as seguintes atividades: Realização de sondagens SPT através de empresa executora, totalizando cinco pontos de perfuração; coleta e padronização de amostras de solo a cada metro do SPT; determinação da umidade base seca do solo.

\section{Palavras-chave:}

Geotecnia, Sondagem SPT, Mecânica dos Solos.

\section{Introdução}

Para a construção de fundações é necessário a determinação da capacidade de carga do solo. Para isso é possível correlacionar o ensaio de SPT e outros ensaios laboratoriais com as propriedades geotécnicas do local. O SPT é uma sondagem por meio de impactos padronizados que relaciona o número de golpes por avanço da profundidade da sonda com o índice de penetração do solo. ${ }^{[1][2]}$

\section{Resultados e Discussão}

O campo experimental foi amostrado em cinco diferentes pontos seguindo a norma NBR 8036. Para os ensaios laboratoriais foram coletadas amostras de solo a cada metro perfurado de um dos furos durante a sondagem SPT. ${ }^{[3]}$

Com os dados de profundidade e mudança das camadas do perfil do solo foi possível estimar o perfil geotécnico espacialmente.

Figura 1. Perfil geotécnico do campo experimental.

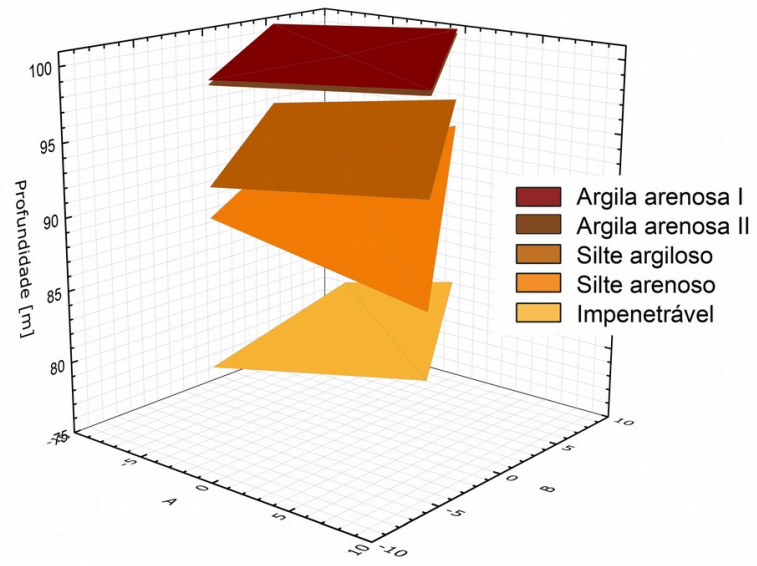

O perfil geotécnico apresentou similaridade com estudos antecessores em solos da região, apresentando características de Latossolo vermelho, frequente no Estado de São Paulo. O nível d'agua foi determinado em dois pontos de sondagem, sendo encontrado a $17,40 \mathrm{~m}$ de profundidade.
Os primeiros cinco metros de profundidade são de solo coluvial, e é possível identificar a mudança das propriedades em relação ao solo residual sobre o qual esse está depositado. Os dados geotécnicos são apresentados na Figura 2.

Figura 2. Características geotécnico do campo experimental.

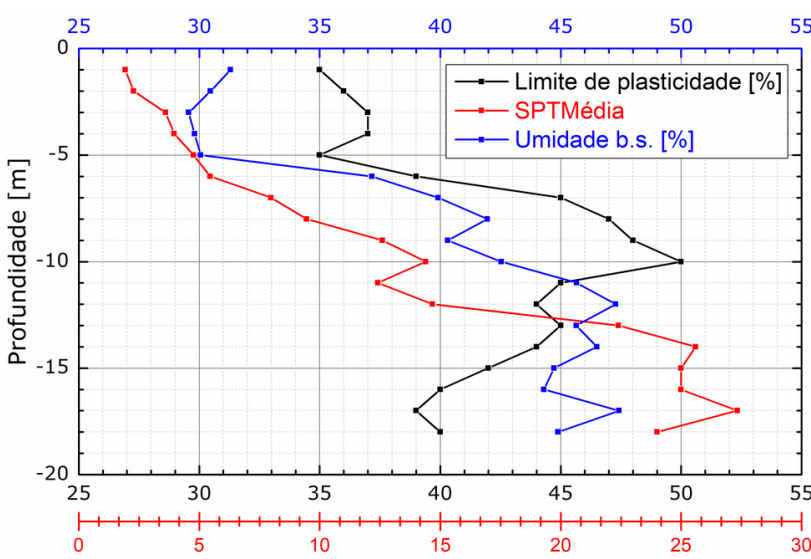

Conclusão

Infere-se que: o índice de resistência à penetração do solo aumenta com a profundidade; a umidade do solo é constante até 5 metros; os limites de plasticidade são maiores nas camadas de argila e reduzem a medida que se avança nas camadas de silte.

\section{Agradecimentos}

Ao apoio financeiro do CNPq e ao apoio técnico dos: Lab-Solos e Lab-Estruturas da FEAGRI; Lab-Solos da FEC.

\footnotetext{
${ }^{1}$ Gon, Fernanda dos Santos. Caracterização geotécnica através de ensaios de laboratório de um solo de diabásio da região de Campinas/SP / Fernanda dos Santos Gon. -- Campinas, SP: [s.n.], 2011.

${ }^{2}$ Peixoto, Anna Silvia Pacheco. Estudo do ensaio SPT-T e sua aplicação na prática de engenharia de fundações / Anna Silvia Palcheco Peixoto. --Campinas, SP: [s.n.], 2001.

3 ASSOCIAÇÃO BRASILEIRA DE NORMAS TÉCNICAS - ABNT NBR8036: Programação de sondagens de simples. Rio de Janeiro, ABNT, 1983
} 